\title{
NURTURING PRE-SERVICE TEACHERS' MINDFUL PERSISTENCE THROUGH VISUAL ARTS
}

\author{
Michael Flannery \\ Marino Institute of Education (Ireland)
}

\begin{abstract}
Persistence is deemed to be a critical disposition for 21 st century learners, graduates and educators. Those who master persistence are abler in today's innovation-driven and ever-changing world to work through challenges and adversity, deal constructively with failure and achieve their goals and outputs from mindful and sustained effort. While persistence features as critical character quality in numerous contemporary early years' and life-long learning frameworks, far less attention is paid to developing persistence in schools, universities and teacher education to combat attrition rates from education and the teaching profession. Therefore, it is important that all educators progress learner persistence in authentic and effective ways. As the creative process of making visual art both demands and teaches the creative habit of mind persistence, this explorative practitioner research evaluates the effectiveness of a visual arts-based initial teacher education programme component with regard to increasing pre-service teachers' persistence. Methods include qualitative content analysis of seventy participants' written reflections regarding what creative habits of mind increased as a consequence of the creative process. Findings indicate that the visual arts learning experience was especially effective in increasing persistence with respect to tolerating uncertainty, sticking with difficulty and daring to be different. Other findings indicate that the creative process, prolonged time, appropriate scaffolding, peer interaction, display of work in progress and teacher belief aided this improvement. In addition, it increased their appreciation of this transdisciplinary disposition and the need for them as teachers to model and monitor persistence in future classroom practice. While appreciating conclusions are context specific, the case study does provide impetus for additional wider research on both student and teacher persistence development in schools, universities and teacher education.
\end{abstract}

Keywords: Persistence, Research projects, Self-efficacy theory, Teacher education, Visual arts.

\section{INTRODUCTION}

Nothing in the world can take the place of persistence...Talent will not...Genius will not... Education will not...Persistence and determination alone are omnipotent.

Calvin Coolidge, 30th US President [1]

Persistence is deemed to be a critical and transversal disposition for 21st century learners, graduates and educators [2] [3] [4]. Those who approach challenges and adversity with persistence, curiosity and initiative are deemed better equipped to succeed in learning, teaching and other professional work. Persistence enables them to achieve goals and outputs from mindful and sustained effort, find effective solutions to problems encountered and perceive failure as a learning opportunity [5] [6]. Notwithstanding that persistence features as critical character quality in numerous contemporary early years' and life-long learning frameworks, far less attention has been paid to developing persistence in schools, universities and teacher education [7] [8]. This is unfortunate as it is very necessary to combat attrition rates from education, the teaching profession and other challenging professions [9] [10]. Much has been written about the value of arts education in terms of developing studio or creative habits of mind and their application to other non-arts domains and disciplines [11] [12] [13]. One of these is persistence, which encompasses three sub-habits of sticking with difficulty, tolerating uncertainty and daring to be different [11] [13] (Fig.1). This practitioner research explores the potential of utilising visual arts to increase pre-service teacher persistence. 
Studies indicate that level of self-efficacy influences the degree of commitment and persistence to a task, role or context [14] [15]. Self-efficacy refers to an individual's beliefs about one's capabilities to exercise control over events that affect their lives and it determines how one thinks, feels and behaves. Self-efficacious individuals have both a positive sense of agency and confidence in their capacity to succeed with their ideas and overcome obstacles. They also have a more open and flexible mindset to learn and stretch beyond their current capabilities as demanded. They acknowledge brain plasticity and understand that every brain is capable of making dramatic changes and leaps in learning [16] [17]. Level of self-efficacy affects and shapes motivation, confidence and critical character dispositions including persistence. If society wishes to combat attrition rates from education, the teaching profession and other challenging careers, then teaching persistence ought to be one of the principles of good practice in education and all educators should model and teach persistence more concertedly throughout their programmes [18] [19] [20]. Consequently, a key motivation behind this practitioner research is to help pre-service elementary teachers more ably persist with the daily challenges and setbacks at university, during their various school placements and when qualified, teach it to future generations.

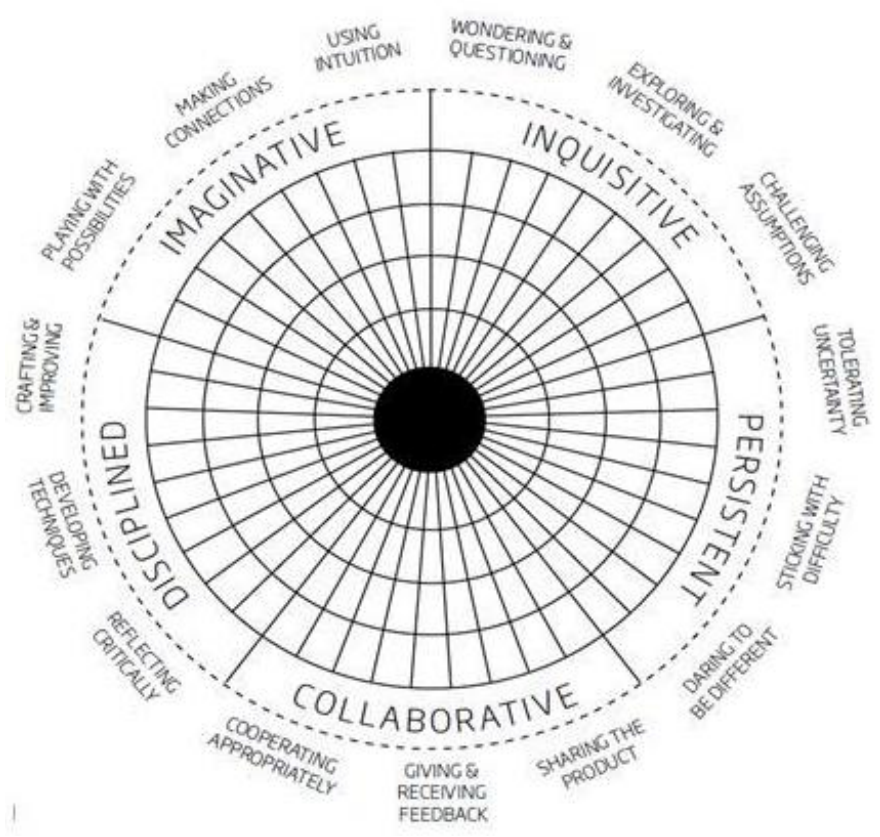

Figure 1. Five Creative Dispositions Model

The theoretical framework underpinning this research and related module component derives from self-efficacy theory. Self-efficacy theory posits that level of self-efficacy is influenced by four sources. These include direct experiences of mastering the challenge, verbal feedback from influential people, vicarious experiences such as observing other role models in action and one's general emotional and physiological state [19] [20]. In this study, the vicarious experience entails looking at, and learning from artwork by the Swiss-German artist Paul Klee (Fig. 2) and the mastery experience involves creating their own artwork entailing approximately twenty hours of self-directed creativity. Paul Klee (1879-1940) was selected as the stimulus as his biography, practice and repertoire of work reflects the essence of persistence. Acknowledged, for example, as a father of abstract art and a forerunner of Surrealism, the mystical hieroglyphs and otherworldly creatures that populate his diverse work also illustrates how he dared to be different. 

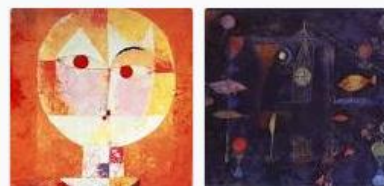

Fish Magic

1925

1922

1922

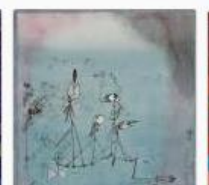

Twittering

Machine 1922

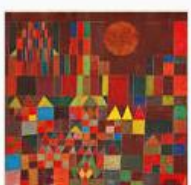

Castle and

1928

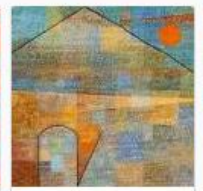

Ad Parnassum

Ad Parnassum

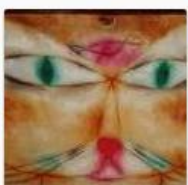

Cat and Bird

1928

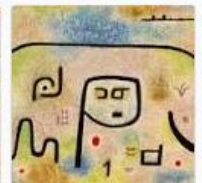

Insula

Dulcamara 1938

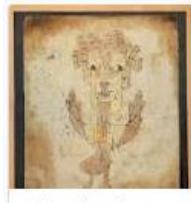

Angelus Novus 1920

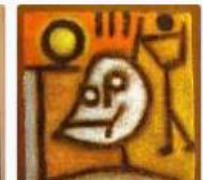

Death and Fire 1940

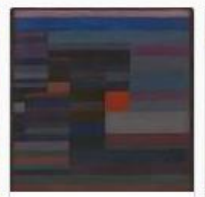

Fire evening 1929

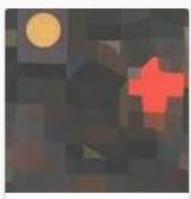

Fire, Full Moon 1933
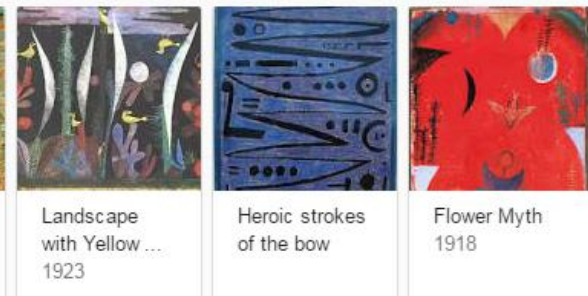

Heroic strokes of the bow

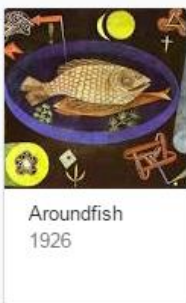

Figure 2. Screen prints of Paul Klee's paintings from a "Google images" search

The learning theories informing the visual arts orientated programme component include social constructivism [21] and creative flow theory [22] [23]. From as constructivist standpoint, the teacher scaffolds learning processes in a manner that enables the learner to progress and flourish. A scaffold refers to any support offered to learners so they enter the zone of proximal development, where learning takes place. Very simply, the zone of proximal development (ZPD) is the difference between what learners can do without help and what they cannot do. The strategy of scaffolding is tailored to each learners' ZPD as it provides just enough temporary supports to permit learners perform the task successfully. According to both theories, level of challenge in teaching and learning is paramount. Creative flow theory theorizes that all learners are happiest when they are in a state of "flow". This is a state of concentration and complete absorption where learners feel and perform our best. Importantly, to achieve a state of flow, the teacher must achieve a balance between the challenge of the task and the skill level of the learner. Pitching a challenge too high can deflate learner self-efficacy and setting it too low may trigger apathy or boredom. Appreciating that the majority of participants have foundational subject knowledge and artistic skills, the menu of techniques explored in the programme component derives from the junior elementary visual arts curriculum [24]. Other features of the learning experience that aligns well with social constructivism is the self-directed nature of the task and the social dimension of learning accommodated via a shared art room resource.

\section{METHODLOGY}

A qualitative approach was selected for this study because this method allows for deep and rich analysis of text and image not so easily obtainable from survey-based research [25]. The essence of qualitative content analysis is identifying substantive statements that really reveal something to the researcher. In this case, substantive statements comprise of significant written content from participants' reflections and the visual narratives, motifs and techniques manifested in their artworks [26] [27]. Both inductive and deductive approaches are adopted [28]. Inductive content analysis is used to identify patterns across participants' artworks with regard to how Paul Klee's repertoire of work influenced participants' artworks and to what programme component affordances they attribute any increased persistence. Deductive content analysis is used with regard to measuring the degree of completeness and originality of participants' artwork using Nilsson's taxonomy of creative design and Jesson's criteria for assessing creative work [29] (Tables 1 \& 2) and for determining what creative habits of mind improved as a consequence of the programme component. This study hypothesises that the very nature of the creative process in making visual art and all it entails teaches persistence as self-doubt, disappointment and dilemma can invade inspiration, ideation, imagination, creation and evaluation of a piece [29]. Both approaches required preparing, repeated "reading", memoing, organising, reducing and recording to assist in drawing conclusions. 
Table 1. Taxonomy of creative design (Nilsson, 2012)

\begin{tabular}{ll}
\hline Level & Description \\
\hline Imitation & The replication of previous work \\
Variation & The modification of existing work \\
Combination & The mixture of two or more forms \\
Transformation & The translation of a work into another medium or mode \\
Original Creation & The creation of something previously unrecognisable \\
\hline
\end{tabular}

Table 2. Assessing Creative work (Jesson, 2012)

\begin{tabular}{ll}
\hline Process involved & Assessment \\
\hline Copies & Replicates given ideas. No reflection. \\
Develops & $\begin{array}{l}\text { Uses given ideas and adds some of their own, and those of } \\
\text { others. Little reflection. }\end{array}$ \\
Extends & $\begin{array}{l}\text { Working from a given starting point, adds many ideas to their } \\
\text { own. Work shows some reflection. }\end{array}$ \\
Innovates & $\begin{array}{l}\text { Does something completely unexpected and different from } \\
\text { everyone else. High degree of reflection. }\end{array}$ \\
\hline
\end{tabular}

\subsection{Participants and procedures}

Participants comprised of seventy pre-service elementary school teachers who already completed thirty hours of visual arts education as part of their first two years of their four undergraduate Bachelor of Education degree. They were also knowledgeable of Claxton, Lucas and Spencer's Creative habits of mind wheel and Hetland et al's "Eight studio habits" of mind from a prior lecture presentation. Each participant was challenged to create a piece of art $50 \mathrm{~cm} \times 150 \mathrm{~cm}$ on fabric cloth that incorporated drawing, print, paint and creative textile elements inspired by work of the Swiss artist Paul Klee. Focusing on one artist was deemed important in order to ascertain and compare levels of originality of their final design and to determine more robust conclusions as to whether the vicarious experience of looking at the artwork of a more expert artist acted as an appropriate scaffold as theorised by selfefficacy theory. Participants completed their work in a self-directed manner over a ten-week period. They worked at their own pace, in their chosen space and in their own time. They had access to relevant art media and materials and to an art room for a minimum of ten hours over a ten week period. Most participants availed of this facility while others opted to progress their work at home or in their campus accommodation. Upon completion, they reflected on, and wrote about their work and learning derived from the experience in relation to studio habits and creative habits of mind (Fig. 3). While the project was a compulsory programme component, participation in the research was voluntary. Artwork submissions were anonymous and related written reflections about the learning experience was confidential.

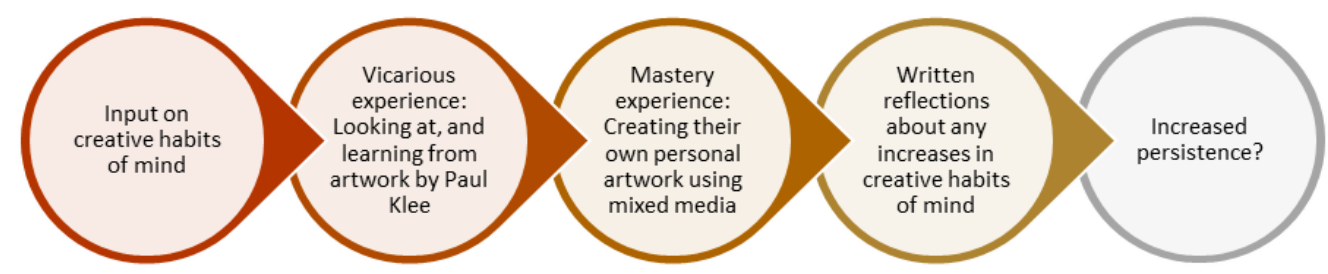

Figure 3: Description of learner experience 


\section{RESULTS}

Paul Klee produced a huge body of diverse work so it is not so surprising that participants selected very different pieces to inform their artwork. Eight participants selected was the figurative landscape "Castle and Sun" (1928) composed of striking geometric shape. Five participants chose the humorous portrait "Senecio" (1922). Five participants the colourful "Landscape with Yellow Birds" (1923). Apart from that, they selected widely from his extensive repertoire in a very personal way. Interestingly, there were some highly popular Klee pieces that did not feature. The majority selected three paintings to inspire their creativity. Content analysis of written work about their artwork and the actual pieces evidence why and how they incorporated some of what observed into composition. Some described how they took specific motifs from Klee's work such as birds, the moon, a castle structure, fish, trees and sail boats. More often, participants wrote how they were inspired not by what he painted but how he painted. Some talked about taking a line for a walk. Other participants talked about adopting his use of simple geometric shape to create complex structures. Many participants talked about adopting is use of colour and love of pattern making. They appeared to select elements from his figurative work to express particular narratives and the abstract pieces for pattern embellishment and background.

\subsection{Quality of work in relation to originality and persistence}

Analysis of participants' artworks using Nilsson's taxonomy of creative design (2011) reveal that there was little imitation of Klee's work (Fig. 4 \& 5). Instead participants modified the aforementioned Klee motifs in highly personal ways. With exception of a few copies of the figure "Senecio", instead of imitating, participants favoured varying, combining, modifying or transforming elements of what they saw into highly original creations. Consequently, every artwork was unique with respect to content, form, mood and meaning. Examples of varying entailed modifying Klee motifs and techniques using their signature style. Examples of combining involved mixing elements, characters or landscapes from two or more of Klee's paintings into one piece. Examples of transforming comprised of exploring Klee's motif and pattern using other media such as print or fabric and fiber effects.

For example, no two participants combined elements from the same Carrington paintings to create their art cloth. Only a few participants sought inspiration from a single Carrington painting. Transformation was also prevalent as participants recreated Carrington's maze, spiral and solar motifs using different media to paint such as print or creative textile effects. Crucially, from the study perspective, the vast majority of participants depicted creative and original hybrid figures or composite animals which threaded Carrington's work and situated them in creative and original surreal settings conjured by their own imaginations resulting in work that and surpassed their expectations. The findings dispel the misconception shared among many practising teachers that exposure to other work somehow curtails learner's creativity. Examining their work in relation to Jesson (2012), the vast majority of participants extended or innovated. For example, despite working from a given starting point, participants added many ideas to their own, they achieved something completely unexpected and different from everyone else underpinned by a high degree of reflection.
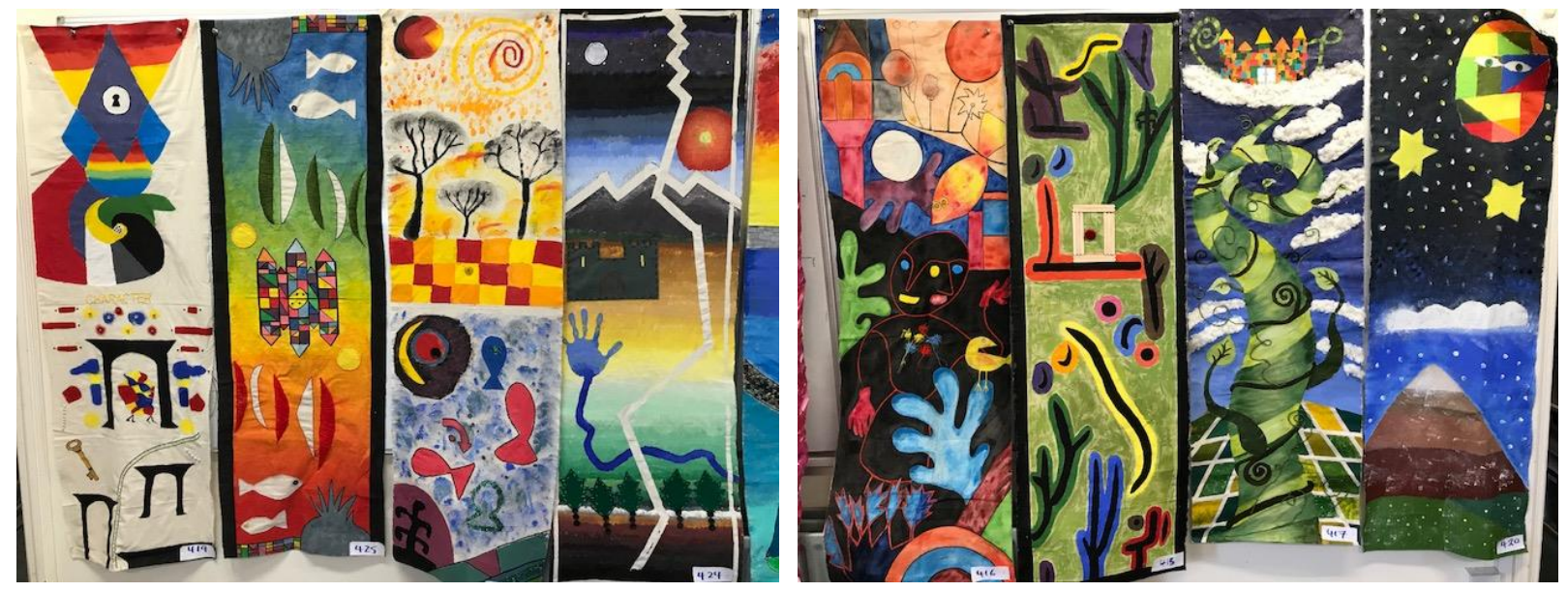

Figure 4. Photographs of participants' artwork 

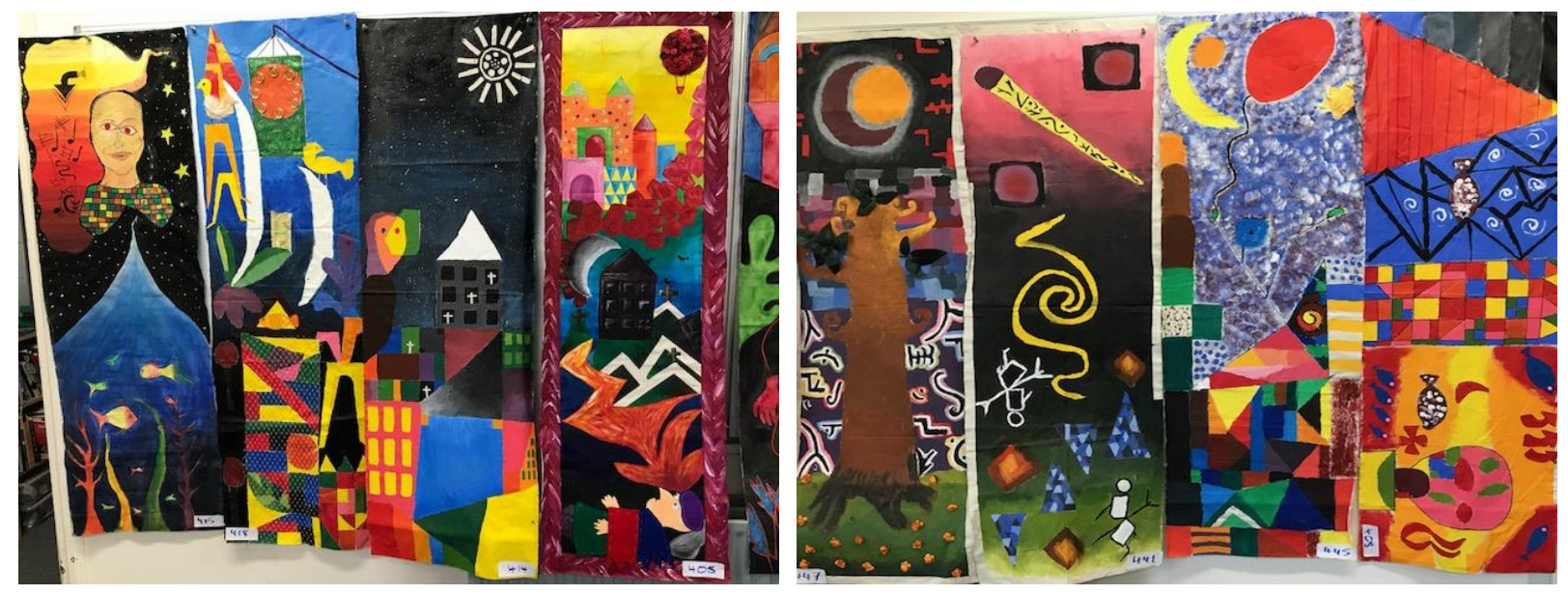

Figure 5. More photographs of participants' artwork

\subsection{Impact on persistence development}

Having completed their piece, participants were invited to write a paragraph about their artwork and outline which creative habits of mind or studio habits improved as a consequence of the project and ascertain why. Three quarters of respondents wrote about persistence. Many wrote candidly about the fact that prior to this experience, they had difficulty with persisting with a task. They described how they found it difficult to settle into an activity or focus on a task. Others explained that they had no previous experience of attending to a challenge for this duration. They described how their persistence evolved as their piece developed. Participants revealed personal gains in all three sub-habits including sticking with difficulty, tolerating uncertainty and daring to be different in equal measure, but relating their development to different stages of the creative process. For example, tolerating uncertainty and daring to be different appeared to be more challenging for many at the beginning of the creative process. Whereas, sticking with difficulty featured more midway as they became impatient with progress achieved in relation to effort made or when comparing creative outputs with other people's progress. Many shared about the different dilemmas they encountered with respect to design and how they had to use other creative habits of mind to help their persistence including self-discipline, collaboration and imagination. Many remarked that as the increased their persistence, they enjoyed the experience more and were sufficiently proud of their final piece. A few participants noted that they had acquired a greater appreciation for the artistic process, for what artists do, for arts education in relation to increasing their persistence and would endeavour to model, mentor and monitor children's persistence development more in their teaching.

\subsection{Affordances that increased persistence}

Content analysis of participants' written reflections also revealed to what programme affordances they attributed any increase. A number of variables came to light (Fig. 6). While all participants wrote very positively about what creative habits and studio habits they progressed as a consequence of project, three quarters mentioned about persistence specifically. They detailed how the creative process itself posed dilemmas and challenges which necessitated persistence. Secondly, time was mentioned very frequently. While the project was time consuming they conceded that it was therefore absorbing, enjoyable and memorable. More importantly, they felt prolonged time was very necessary to feel any improvement in persistence as character qualities take time to evolve. Thirdly, while the scaffold of looking at and learning from work by Paul Klee was deemed effective with respect to developing their creative self-efficacy, participants wrote more about the value and impact of informal peer encouragement, feedback and modelling in term of enabling them to persist. In addition, they explained how the incidental display of preservice teachers' works in progress in the art room propelled their persistence further as a consequence of comparing level of progress, quality of design and standard of creativity among the group. Some wrote how beneficial the access to the art room from a social interaction and appropriate workspace perspective. Finally, many wrote how they appreciated the self-directed and self-determined format of the project design which signalled that the teacher/ researcher had faith in their capability and trusted their capacity to persist with the challenge. 


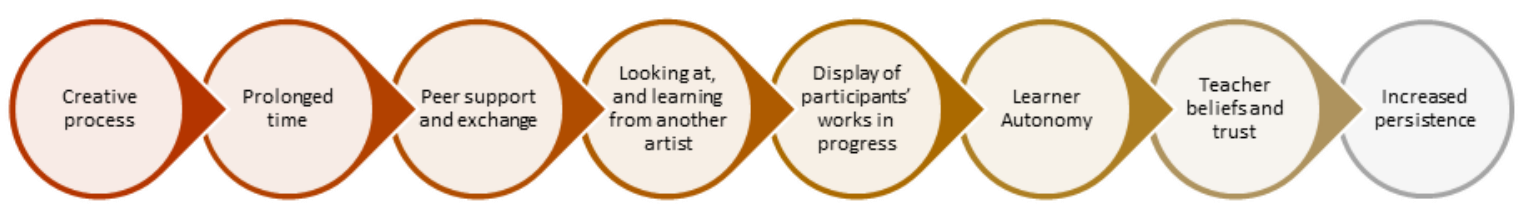

Figure 6. Programme affordances that nurtured persistence

\section{CONCLUSIONS}

Notwithstanding the limitations of a case study with respect to generalisability, this practitioner research concludes that persistence development was achieved with many participants through visual arts. Three quarters of participants described this increase in a number of ways including sticking with difficulty, daring to be different and tolerating uncertainty. Participants who recorded an increase in their persistence attributed this progression to a number of variables. Firstly, the mastery experience/ creative process of inspiration, ideation, creation and evaluation and all it demanded was a key variable. Secondly, looking at, and learning from Paul Klee's extensive repertoire of artwork acted as a very effective vicarious experience, stimulus and scaffold. It determined that looking at, and learning from creative work by a more knowledgeable or experienced person nurtured and inspired original creation and persistence. While participants imitated a number of Klee renowned motifs and techniques, the vast majority modified, combined or transformed them in highly personal ways. As one participant recorded, it debunked a common misconception among the teaching profession that exploring motifs and techniques from other artworks somehow dilutes learner self-expression or curtails creativity.

Thirdly, looking at, learning from and liaising with peers was deemed to be a powerful determinant. The researcher notes that it would have been interesting to discover whether mobile messaging applications such as Snapchat, Viber or WhatsApp were used as conduit for such peer modelling, motivation and mentoring as well as the social interaction in the art room. Another important factor were the incidentals displays of works in progress in the art room. When works in progress were left hanging to dry in the art room, participants recorded that such informal exhibitions enabled them to ascertain standards, compare progress, borrow techniques and evaluate how others incorporated Klee motifs or techniques into their work. They increased their persistence also. Fourthly, what was especially effective in increasing participants' persistence was time. Many recorded that prior to this, they never worked on a project over such a sustained period of time. Several wrote how time enabled them to overcome their initial apprehensions about making mistakes, self-doubts regarding their creative self-efficacy, frustrations regarding perceived lack of progress or design difficulties and nervousness about being different to others. Persistence evolved as the pieces evolved. By gifting prolonged time to one artistic project, participants could see tangible evidence in their artwork of improvements with regard to their creative abilities and persistence. Finally, the self-directed and selfdetermined nature of the learning experience and teachers/ researchers' belief in their capacity to persist were also identified factors. With increased learner autonomy came increased learner responsibility. Belief and trust in participants' creative and persistent potential became a self-fulfilling prophecy.

Multiple implications arise from this research. Firstly, that persistence requires modelling, mentoring and monitoring in education and teacher education so that learners and student teachers can develop persistent self-efficacy to persevere all the challenges that learning and teaching entails. Secondly, the arts should be explored more in terms of developing other transferable creative habits of mind pertaining to collaboration, discipline, imagination and curiosity, which are all deemed critical to twenty-first century learners and graduates. Thirdly, by taking persistence development more seriously in teacher education in both a concerted and communicative way, teacher graduates will be more inclined to appreciate such dispositions and model them in their classrooms. Fourthly, irrespective of discipline, providing less but extended learning experiences that entail creative processes and affording opportunities and spaces for peer collaboration and exchange can be highly effective in developing transversal character qualities such as persistence. 


\section{REFERENCES}

[1] Quotation attributed to Calvin Coolidge, 30th US President; Retrieved from https://philosiblog.com/2014/02/24/nothing-in-the-world-can-take-the-place-of-persistence, 2014.

[2] World Education Forum. New Vision for Education Report, Retrieved from http://www3.weforum.org/docs/WEFUSA_NewVisionforEducation_Report2015.pdf, 2015.

[3] Scott L. "21st Century Skills Early Learning Framework". 21st Century Learning For Early Childhood. Partnership for 21st Century Learning (P21), 2017.

[4] Pešikan A \& Lalović Z. Education For Life: St Key 21 Century Competencies In Curricula In Montenegro Executive Summary, UNICEF Montenegro, 2017.

[5] Bernacki ML \& Nokes-Malach TJ. "Examining self-efficacy during learning: Variability and relations to behavior, performance, and learning". Metacognition Learning, vol. 10, pp. 99-117, 2015.

[6] Evans-Palmer T. "Building dispositions and self-efficacy in pre-service teachers", Studies in Art Education, vol. 57, no. 3, pp. 265-278, 2016.

[7] Chemers ML \& Garcia B. "Academic self-efficacy and first-year college student performance and adjustment”, Journal of Educational Psychology, vol. 93, no. 1, pp. 55-66, 2001.

[8] Claybrooks SG \& Taylor FP. "Student persistence and use of a college success course in proprietary postsecondary education", Higher Education Abstracts, vol. 51, no. 4, pp.359-363, 2016.

[9] Wheatley K. "Teacher persistence: A crucial disposition, with implications for teacher education", Essays in Education 3, pp. 1-13, Retrieved from https://www.researchgate.net/publication/268441017, 2008.

[10] Huntley A \& Donovan J. "Supporting the development of persistence: Strategies for teachers of first year undergraduate students", International Journal of Teaching and Learning in Higher Education, vol. 21, no. 2, pp.210-220., 2009.

[11] Claxton G, Edwards L \& Scale-Constantinou V. "Cultivating creative mentalities: A framework for Education”, Thinking skills and Creativity, vol. 1, pp. 57-61, 2006.

[12] Winner E, Hetland L, Veenema S, Sheridan K, Palmer P, Locher I, et al. "Studio thinking: How visual arts teaching can promote disciplined habits of mind", New directions in aesthetics, creativity, and the arts, pp. 189-205, 2006.

[13] Lucas B. "A five-dimensional model of creativity and its assessment in schools", Applied Measurement in Education, vol. 24, no. 9, pp 278-290, 2016.

[14] Lahmers A \& Zalauf C. "Factors associated with academic time use and academic performance of college students: A recursive approach", Journal of College Student Development, vol. 41, no. 5, pp. 544-556, 2000.

[15] Halper LR \& Vancouver JB. "Self-efficacy's influence on persistence on a physical task: Moderating effect of performance feedback ambiguity" Psychology of Sport and Exercise, vol. 22, pp. 170-177, 2016.

[16] Compeau DR \& Higgins CA. "Application of social cognitive theory to training of computer skilss", Information Systems Research, Vol. 6, no. 2, pp. 118-143, 1995.

[17] Kefallinou M. "The Learner Persistence Project at Quinsigamond Community College". Adult Basic Education \& Literacy Journal, vol. 3, no. 2, pp. 105-109., 2009

[18] Hensley LG. "Rethinking Adult Learner Persistence: Implications for Counselors". Adultspan Journal, vol. 3, no. 2, p. 88. 2001.

[19] Claxton G. "Cultivating positive learning dispositions" in Routlede Companion to Education (Daniels H, Lauder H \& Porter J eds.) 177-187., London: Routledge, 2008. 
[20] Prendergast D, Garvis S \& Keogh J. "Pre-service students teacher self-efficacy beliefs: An insight into the making of teachers, Australian Journal of Teacher Education, vol.36, no. 12, pp.46-57, 2011.

[21] Jordan A, Carlile O \& Stack A. Approaches to learning: A guide for teachers. McGraw-Hill, Open University Press: Berkshire. 2008

[22] Beard KS. "Theoretically speaking: An interview with Mihaly Csikszentmihalyi on flow theory development and its usefulness in addressing contemporary challenges in education", Educational Psychology Review, vol. 27, no.2, pp.353-364, 2015.

[23] Csíkszentmihályi, M. Flow: The psychology of optimal experience. New York: Harper Perennial; 2008.

[24] National Council for Curriculum and Assessment. Visual Arts Education Primary Curriculum, Dublin: Government of Ireland, 1999.

[25] Castleberry A, Payakachat N, Ashby S, Nolen A, Carle M, Neill K \& Franks A. "Qualitative analysis of written reflections during a teaching certificate progam" American Journal Of Pharmaceutical Education, vol. 80, no. 1, article 10, 2014.

[26] Vaismoradi M, Turunen H \& Bondas T. "Content analysis and thematic analysis: Implications conducting a qualitative descriptive study", Nursing and Health Sciences, vol. 15, pp. 398-405, 2013.

[27] Elo S \& Yngas H. "The qualitative content analysis process" Journal of Advanced Nursing. Vol. 62, no. 1, pp. 107-115, 2007.

[28] Ahmed JU. "Documentary research method: new dimensions", Industrial Journal of Management and Social Sciences, vol. 4, no. 1, pp. 1-14, 2010.

[29] Jesson J. Developing creativity in the primary school. Berkshire: Open University Press, 2012. 